\title{
The Holistic Approach to Clinical Problem Using Fishbone Format: A Simple Way for Clinical Reasoning
}

\author{
Omar AR Bawazir \\ Hadramout University College of medicine (HUCOM), Hadramout / Yemen, Mukalla.
}

\begin{tabular}{ll}
\hline ARTICLE INFO \\
Received & $: 23 / 01 / 2014$ \\
Accepted & $: 07 / 07 / 2014$ \\
Published & $: 01 / 09 / 2014$
\end{tabular}

\section{KEYWORD}

Clinical reasoning

Medical problem solving

Fishbone

Pattern of recognition

Problem based learning

Skills lab (Clinical Skills

Centre)

Teaching/learning

Medical Education

\begin{abstract}
Introduction: Clinical reasoning (CR) is the cornerstone of medical curricula. It is the cognitive process of solving patient's problem. Different teaching methods are advocated to teach clinical reasoning. Each has its advantages and disadvantages. Aim: to introduce and discuss the fishbone format as a systematic structured method to enhance teaching and learning of clinical reasoning to medical students in different teaching settings. Method: The format consists of a head, six bones and the tail. The head represents the presenting problem or complaint; the bones represent the different steps of the clinical reasoning. The first bone of defining the presenting problem is expanded to include the basic sciences. In addition we add a sixth rib for complication/prognosis and the tail is kept for the prevention. Results: The format can be used in different teaching settings such as, lecture theatre, small group discussion, tutorial, skills lab, and clinical settings. It will help preceptors to facilitate and guide teaching of clinical problem in a holistic logical sequence. It encompasses both models of clinical reasoning, pattern of recognition and the hypothetico-deductive one. Conclusion: This is a simple schemata aims to guide trainers and students to see and learn the full picture of patient management and emphasize on integration rather than isolation of clinical competence domains during teaching activities. Teachers and learners of other fields of science will find it helpful as well.
\end{abstract}

(C) Medical Education Department, School of Medical Sciences, Universiti Sains Malaysia. All rights reserved.

CORRESPONDING AUTHOR: Dr Omar Abdul-Rahman Bawazir, Hadramout University College of medicine (HUCOM), Hadramout / Yemen, Mukalla, P.O. Box 8927. Email: omarbawazir@yahoo.com

\section{Introduction}

Clinical reasoning $(\mathrm{CR})$ is the cognitive process of solving patient's problem and the cornerstone of medical curricula. Researchers have advocated many theories about this process such as the hypothetic-deductive (analytic process) and pattern recognition (non-analytic process or intuitive process) separately or in combination (1). According to Barrows \& Tamblyn (2), it consists of five steps or elements. There is no optimal method to teach clinical reasoning because it depends on both situational and personal factors. Nevertheless, many attempts and strategies are posited to facilitate teaching and learning of clinical solving problems particularly at the early years of the medical schools so as to improve such skill later on (1-6). However, neither of these strategies addresses the clinical reasoning formally and explicitly. 
On the other hand, clerkship students have limited contact time with patients and hardly any reflection at the bedside teaching which compromises their clinical problem-solving capabilities; hence delay of introducing clinical reasoning might be the cause of poor performance of student's medical solving problem (7). These factors urge researchers to develop and submit new thoughts and ideas to address the teaching of CR (8).
This paper explains and discusses the fishbone format and its different elements (Table 1) to facilitate the teaching and development of clinical reasoning and overall patient's management particularly to undergraduate medical students at the different teaching settings.

Table 1: Main elements and description of fishbone format in relation to the model of Clinical reasoning related to that of Barrows \&Tamblyn

\begin{tabular}{|c|c|c|c|}
\hline $\begin{array}{l}\text { Fishbone format } \\
\text { element }\end{array}$ & Characteristics & $\begin{array}{l}\text { Clinical Reasoning Step } \\
\text { (hypothetico-deductive } \\
\text { form) }\end{array}$ & Comment \\
\hline Head & $\begin{array}{l}\text { The presenting complaint, disease's feature or } \\
\text { abnormal result }\end{array}$ & Perception & $\begin{array}{l}\text { Include the non- analytical } \\
\text { form of CR (intuitive) }\end{array}$ \\
\hline First bone & $\begin{array}{l}\text { Define the problem/ disease; include anatomy, } \\
\text { physiology, pathology (mechanism of the clinical } \\
\text { features). }\end{array}$ & & $\begin{array}{l}\text { Ensure explaining the } \\
\text { mechanism of disease }\end{array}$ \\
\hline Second bone & $\begin{array}{l}\text { Etiology/causes/differential diagnosis, in a } \\
\text { broader categories such as: infection, trauma, } \\
\text { metabolic, neoplastic etc. }\end{array}$ & Hypothesis generation & Preferred in generic grouping \\
\hline Third bone & $\begin{array}{l}\text { Clinical picture: detailed history with its main } \\
\text { elements i.e. personal data, chief complaint, } \\
\text { present illness, past medical history, drugs and } \\
\text { allergy, social, and vaccination. Full examination } \\
\text { from head to feet }\end{array}$ & Ranking & $\begin{array}{l}\text { Student has to summarize } \\
\text { relevant points for problem } \\
\text { formulation }\end{array}$ \\
\hline Fourth bone & Investigations: basic and diseased specific & Ranking & \\
\hline Fifth bone & Treatment: supportive and diseased specific & Closure & \\
\hline Sixth bone & $\begin{array}{l}\text { Complications and prognosis: complication due } \\
\text { to the disease or secondary to our intervention. It } \\
\text { is categorized in systemic based approach such } \\
\text { as cardiac, hepatic renal etc. }\end{array}$ & & $\begin{array}{l}\text { Will enhance communication } \\
\text { skills and deep understanding } \\
\text { of disease }\end{array}$ \\
\hline Tail & $\begin{array}{l}\text { Prevention: primary (disease specific) and } \\
\text { secondary (community based) }\end{array}$ & & $\begin{array}{l}\text { Emphasize the community } \\
\text { oriented approach and patient } \\
\text { education }\end{array}$ \\
\hline
\end{tabular}

\section{Fishbone Development}

The idea of the fishbone format began at the skill lab in our medical school (Hadramout University College of Medicine, HUCOM) which adopts problem based learning (PBL) since its establishment in 1997. The skill lab is one of its main functioning units. The skill lab sessions used to teach students the technical aspects of clinical competence in isolation using checklists where students tend to swallow and regurgitate them in the exam. They hardly any receive problem solving skill's approach explicitly. We have changed the session into a clinical problem solving and incorporated the technical skills into it. In addition to the five clinical reasoning steps of Barrows \&Tamblyn (perception, generation of hypothesis, ranking, problem formulation, and 
closure) we add complication/prognosis and prevention to ensure a holistic problem solving approach. On the assessment method, we add to the mini-objective structural clinical examination, paper tests in the form of patient solving problem according to the students' level and block problems.

We have extended our approach to clerkship students who were found to have difficulty in structuring their overall clinical problem solving. They look unconfident and lack the efficient and logical sequence and wander between the different steps of the clinical reasoning and some of them even have difficulty at the starting point. Complication and prevention are nearly forgotten unless they are asked specifically.

The same approach has been applied in the lecture hall and small group discussion including the tutorials.

\section{The fishbone format (Method)}

It consists of a head, six bones and a tail (Fig 1).The format is laid in this form to be easily remembered, absorbed and assessed.

\section{The head}

It is the presenting problem whether a complaint, abnormal result, or a picture. We remind the student that the disease can presents in different scenarios. The head represents the perception step/element of clinical reasoning of Barrows \& Tamblyn. It includes patient's personal data and contextual factors, thereby enabling students to explore and improve their pattern of recognition (intuitive reasoning). An example is a jaundice in a three day old baby will differ from that of an adult.

\section{The above three bones}

It includes definition, etiology, and clinical pictures

\section{The first bone: Define or clarifying the presenting problem}

The definition is expanded to include basic science such as pathophysiology and anatomy so as to help the student to explain and understand the patients' symptoms and clinical signs. An example is chest or abdominal pain,the students have to know the underlying anatomical structures from which the pain could be originated and pathology so as to generate hypotheses.We aim for integration of basic and clinical sciences and focus on the basic mechanism of the disease so as to improve the mental representation of clinical reasoning (9) as well as enhancing and developing the pattern of recognition and initiating the forward reasoning in complex or rare condition (1).

\section{The second bone: Etiology/hypotheses/ differential diagnosis}

It is the generation of hypotheses of the CR which is guided by the basic sciences discussed above. An example is the hypotheses generation of a child with puffiness of the face where the pathophysiology of oedema is defined early in the first bone. We asked the students to think in generic grouping such as renal, cardiac, gastrointestinal etc. rather than specific disease as nephritic/nephrtotic syndrome or heart failure. We augment our session by pictures. Students are asked to confirm or refute the diagnosis or ranking the diagnosis through the next bone using hypothetico-dedcutive approach so as to avoid error of the non-analytic model of CR (1). We try to accommodate the block problems in our hypotheses so as to consolidate and integrate the session with the theoretical discussions given elsewhere in the curriculum.

\section{The third bone: Clinical feature}

It includes the detailed history and physical examination. On the physical examination, the students are actively involved in the process which is supported by pictures, role play, etc. according to the teaching setting. In the small group such as in the skill lab the trainer encourages the group to summarize their finding 
and formulate the problem (problem formulation of CR) and ask one student to present it in front of the whole group so as to improve presentation skill. In the skills lab or clinical setting the students then practice physical examination under the supervision of the trainer. We ask the students to structure their examination from the general examination to specific examination using some of the acronyms to remember if applicable such as JACCOL (Jaundice, Anaemia, Cyanosis, Clubbing, Oedema, and Lymphadenopathy) and AVPU (alert, verbal response, pain response and unresponsive) for assessing mental status. This stage is ended by a summary of the problem into a provisional diagnosis or limited hypotheses and management plan.

\section{The lower three bones}

It involves investigation, treatment (closure), and complication/prognosis.

\section{The fourth bone: Investigations}

This is the complementary step of ranking the hypotheses. We divide it into basic and case specific investigations. The numbers of basic tests vary and the students have to justify their investigations' request and to consider the specificity/sensitivity and the cost of the test so as to improve their reflection and efficiency.

\section{The fifth bone: Treatment}

This is the closure step of CR of Barrows \&Tamblyn. It could be treatment, referral or reassurance. The students have to realize that treatment could be medical, psychological or both for the patients and their relatives. They are taught and reminded to support and stabilize the critically ill patient and surgical conditions before embarking on specific treatment.

\section{The sixth bone: Complication/prognosis}

This is divided into disease and treatment related complications particularly to drugs and invasive procedures or surgery. We prefer systemic approach to complications such as nervous, cardiac, renal, hepatic etc. We encourage our students to discuss the prognosis of diseases so as to improve their communication skills with patients and deepen their understanding of the disease process.

\section{The tail of the fish: Prevention}

This is the end of our holistic management approach and to ensure the community orientation of our curriculum. We divide it into primary and secondary prevention. The primary is related to specific preventive measures of the disease such as immunization (passive and active) and screening for diseases. The secondary measure is related to prevent the spread of the disease which is covered comprehensively by the community department staff. 


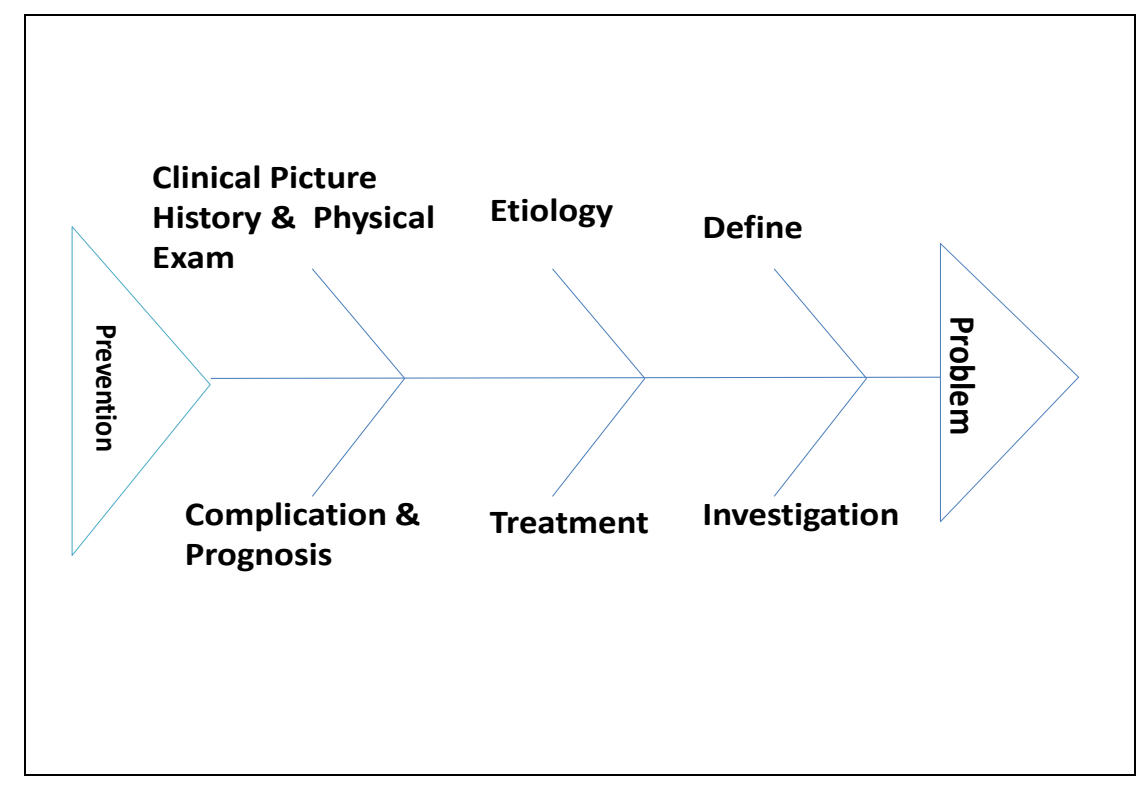

Fig. 1 The fishbone format

\section{Discussion \& Result}

Our fishbone format extends beyond the CR steps of Barrows \& Tamblyn and the schematic diagnostic approach of University of Calgary (CPC 1992). It includes complication/prognosis and prevention and addressed the patient problem holistically and explicitly rather than in fragmented specifics.

Our fishbone incorporates the basic sciences to explain the mechanism of disease and helps understanding the clinical features and adopts reasoning steps of Barrows \& Tamblyn to confirm or refute hypotheses. It helps as well the approach to complex/difficult cases faced the students' intuitive reasoning (1). It will help the teacher to diagnose the student's level of diagnostic reasoning as it involves hypothesis generation and refining by comparing and contrasting (10).

For pre-clerkship students our aim is to introduce and discuss the steps of the CR through the fishbone format, and focus mainly on the above bones and to less extent lower ones.

During application of this approach particularly in the skills laboratory, there were some reservations and hesitancy particularly from second and third year students because of the radical change of the skills lab session and the exam method from the technical aspect into a problem solving one. We try to overcome their skepticism by reminding them our approach is similar to what is adopted in other countries and it is the key element to prepare them for clerkship rotation which will give them the opportunity to think and behave like the experts (11).

I find the approach very helpful to guide and ease my lecture as well as to overcome lecturalagia (12).

The main limitations for implementing such as approach were, the strong internal forces from the laggards resisting the change in the skill lab (13), students' resentment of their low score in the new exam technique particularly the skill lab.

\section{Conclusion}

Data on clinical reasoning remain theoretical and expert opinion, and its understanding and teaching is diverse and complex. Nevertheless, we should keep up the momentum of teaching and learning of clinical reasoning to medical students by using different strategies. Our approach would help early medical students to prepare them to become expert clinical problem solver during their clerkship. 


\section{Practical Points}

- Clinical reasoning is the cornerstone skill of medical schools graduates

- Hypothetico-deductive and pattern separately or in combination are the main forms of clinical reasoning

- The Hypthetic-deductive form is easily constructed and adopted strategy and consists of perception, generation of hypothesis, refining, problem formulation, and closure

- Clinical reasoning could be introduced to early undergraduate medical student through different strategies such as fishbone format

\section{Notes on contributor}

Omar Bawazir, MRCP (UK), is an Assistant Professor of Pediatrics at Hadramout college of Medicine (HUCOM), Hadramout, Yemen. He held different substantial hospital clinical posts in different countries such as the UK, KSA, and UAE from 1995 till 2007. He is a consultant pediatrician at Mukalla Maternity \& Children Hospital at Mukalla, Hadramout, Yemen. He was the director of Skills Training Program at HUCOM from 2007 till 2010. Currently he is on sabbatical leave at University of Sciences\& Technology at Sana'a, Yemen

\section{Acknowledgments}

I would like to thank my colleagues Dr Adnan Milqat, Dr Amira Alkatheri, Dr Omar Birhaish who were the early adopters of this approach and helped me to implement it at Hadrmaout Medical School. I would extend my thanks to Dr Noor Bin Kroom from Maternity \& Children Hospital/Mukalla Hospital/Yemen on her invaluable comments and encouragement during the application of this approach in clinical teaching sessions at the hospital.

\section{Reference}

1. Pelaccia T, Tardif J, Triby E, Charlin B. 2011. An analysis of clinical reasoning through a recent and comprehensive approach: the dual-process theory. Medical Education 16: 5890

2. Barrows HS \& Tamblyn RM.1980.Problem based learning: An approach to medical education (New York, Springer).
3. Eva KW. 2004. What every teacher needs to know about clinical reasoning. Medical Education 39:98-106.

4. Norman G. 2005. Research in clinical reasoning: past history and current trends. Medical Education 39: 418-427

5. Charlin B, Boshuizen HPA, Custers EJ, Feltovich PJ. 2007. Scripts and clinical reasoning. Medical Education 41: 11781184

6. Kassirer JP 2010. Teaching Clinical Reasoning: Case-Based and Coached. Academic Medicine 85:1118-1124

7. Lewkonia RM, Harasym PH, Darwish HZ. 1993. Early introduction to medical problem solving. Medical Teacher 15: 57-65.

8. Borleffs JCC, Custers EJFM, van Gijn J, ten Cate OTJ. 2003. Clinical Reasoning Theatre: A new Approach to Clinical Reasoning Education. Academic Medicine 78: 322 325

9. Schmidt HG, Norman GR, Boshuizen HPA.1990. A cognitive perspective on medical expertise: theory implications. Academic Medicine 65:611-21.

10. Wolpaw T, Papp K, Bordage G. 2009. Using SNAPPS to Facilitate the Expression of Clinical Reasoning and Uncertainties: A Randomized Comparison Group Trial. Academic Medicine. 284:517-524.

11. Monajemi A, Rikers R, Schmidt H. 2007. Clinical case processing: a diagnostic versus a management focus. Medical Education 41:1166-1172

12. McLaughlin K \&Mandin H. 2001. A schematic approach to diagnosis and resolving lecturalgia. Medical Education $35: 1135-1142$ 
13. Rogers Everette M. Diffusion of Innovations. $3^{\text {rd }}$ ed, (New York, Free Press 1963), page, 247 